\title{
The self-evaluation and revision method for homework: a homework method for metacognition improves post-secondary engineering students' attitudes towards homework
}

\section{Major Patrick Alan Linford, The United States Military Academy at West Point, NY}

Patrick A. Linford is a Major in the United States Army, and is currently an Assistant Professor at the United States Military Academy at West Point, New York. He has his Bachelor of Science from the United States Military Academy (2007), and his Master of Science (2017), from The Massachusetts Institute of Technology all in Mechanical Engineering.

\section{Lt. Col. James E Bluman, U.S. Military Academy}

Lieutenant Colonel James Bluman is currently an Assistant Professor in the Department of Civil and Mechanical Engineering at the U.S. Military Academy at West Point. He has served the United States Army for the last 20 years as an officer and Army Aviator. He is a graduate of West Point (B.S. in Mechanical Engineering), Penn State (M.S. in Aerospace Engineering), and the Univ. of Alabama in Huntsville (Ph.D. in Mechanical Engineering). His research interests are in the flight dynamics of VTOL aircraft and UAVs and innovative teaching methods.

\section{Dr. Gregory Martin Freisinger, United States Military Academy}

Greg Freisinger is an Assistant Professor of Mechanical Engineering at the United States Military Academy at West Point. He holds a Bachelor of Science degree from Georgia Institute of Technology, as well as a MS and PhD from The Ohio State University. Greg is an US Army engineer officer in the Reserves with experience in combat and construction engineering and more recently the 75th Innovation Command. His research is primarily focused on engineering education and biomechanical factors associated with injury and performance.

\section{Prof. John R Rogers, U.S. Military Academy}

John Rogers is an engineer and an educator. He solves problems with a balance of theoretical knowledge and experimentation. He has expertise in mechanical analysis and design, electronics, application of sensors and actuators, and microcontrollers. His PhD is in Mechanical Engineering from Rensselaer Polytechnic Institute. He is an Associate Professor at the United States Military Academy, West Point, New York.

\section{Lt. Col. Brian J Novoselich P.E., United States Military Academy}

Brian Novoselich is an active duty Army Lieutenant Colonel currently serving as an Assistant Professor in the Department of Civil and Mechanical Engineering at the United States Military Academy (West Point). He earned his Ph.D. in Engineering Education at Virginia Tech in 2016. He holds Master's and Bachelor's degrees in mechanical engineering from The University of Texas at Austin and West Point respectively. His research interests include capstone design teaching and assessment, undergraduate engineering student leadership development, and social network analysis. He is also a licensed professional engineer in the Commonwealth of Virginia. 


\title{
The self-evaluation and revision method for homework: a homework method for metacognition improves post-secondary engineering students' attitudes towards homework
}

\begin{abstract}
Traditional methods for grading and returning corrected homework to students do not require the student to determine how they erred, learn how to avoid repeat errors, or revise and improve their work. Educators know that multiple focused reviews of material are often required for learning analytically difficult material. Even when educators provide detailed feedback and corrections, many students look at the grade on a homework assignment without review and put it away until exam study time. The result is a missed opportunity for the student to more fully understand details they have yet to master, and the time the instructor spent making corrections is wasted.
\end{abstract}

In the self-evaluation and revision method for student homework students complete their homework and submit an electronic copy. A solution is then given to students who mark and correct their work, give their original work a grade, and submit the self-evaluated and reviewed work. This system applies a direct principle for good undergraduate engineering practice: it provides prompt feedback and it also applies three indirect principles by developing cooperation among students, encouraging active learning, and communicating high expectations.

The purpose of this study is to investigate the effect of the self-evaluation and revision homework system on student learning and attitude for three mechanical engineering courses at the United States Military Academy (USMA) at West Point, NY. A fourth-year course on vibration engineering across five semesters that has implemented the system over several years $(n=49,34$, $37,43,16$ students), a fourth-year course on control systems across a single year $(\mathrm{n}=34)$ and a third-year course on rigid body dynamics across one semester $(n=38)$ are included in the study. The students in the courses were surveyed multiple times during the semester to determine if there had been any changes in their attitude toward the method within a semester and between courses.

Introduction

Homework is a part of the academic experience that no one seems to like. To students, homework represents a burden of time, energy and often frustration. To faculty, homework also represents a burden - instructors must find, write, and assign homework. Then they must assist students who visit them during office hours. And if the homework is to be graded, they must grade it or pay a teaching assistant to do so for them. Even then, the work associated with homework is not over. Many faculty have experienced visits from students who are confused by the grading or who object to some aspect of their grade. However, homework also represents a primary way that student's learn new material. Additionally, homework that achieves elements of metacognition has been proven to increase learning[1].

This is a study of a method that enforces self-evaluated and revised student homework that was used at the United States Military Academy (USMA) over the course of four years in upper level mechanical engineering classes. Students completed a homework assignment by the due date. 
They then scanned and digitally submitted their work to the instructor (via email or an online submission portal through a Learning Management System). This established a record of what they accomplished on their own. After the initial due date had passed, the instructor published a solution. Students then reviewed the solution, marked their own errors, and made corrections within their homework. After completing all the corrections, they assessed their overall understanding of the material and assigned a letter grade (e.g. a A- or a C+). They then submitted their corrected, revised, and graded copy prior to a final due date a few days after the first due date, usually in hard copy. A certain percentage of the points is based on their first attempt, and the remaining points are given based on the quality of their corrections.

\section{Background and motivation}

Strong evidence suggests that learning highly technical and abstract information requires multiple repetitions with students attending to the details as well as accessing higher levels on Bloom's taxonomy of the cognitive domain. Graded assignments must be deliberate and often are the only practical way to both assess and reinforce course material[2]. Further, a student's individual effort solving problems most strongly related to higher exam performance in a mechanics course[3]. However, finding practices that encourage repeated attention and review are difficult, despite work that showed that review of tests demonstrated learning after the test[4].

While the utility of homework in primary and secondary education has been in doubt throughout the years[5], it has been an effective tool at the post-secondary level to provide learning beyond the restricted time for scheduled classes. The platform for homework (online vs paper, writing vs worked problems, etc.) has had mixed resulted in the literature[6], [7], [16], [17], [8]-[15]. When homework has been used effectively, it typically required a grade[18], self or peer review[19] and uses metacognitive tools[1], [20]. Chickering and Gamson established seven principles for good practice in undergraduate education[21]. This study directly follows one (give prompt feedback) and indirectly supports three of the principles (develop cooperation among students, encourages active learning, and communicates high expectations).

Homework facilitates learning and it can also be used to assess learning. Students can demonstrate their mastery of concepts, while self-study allows them to apply knowledge in new ways on problem sets. The complexity of the problem set encourages students to engage the material multiple times as well as understand how that material fits into the context of the course. In a previous study, some of the authors explored a method to enforce completion of homework by requiring students to re-work homework problems until they were correct[22]. The grade was based on how many iterations were required for the student to get the correct result. The study found that the students self-reported high rates of retention. It also found that the method was a good use of the students' time despite the potential for it to take more time. Test results, however, did not show a measurable improvement. Furthermore, this method of homework grading also created additional time burden for the instructor.

Davis recommended that faculty "give students a chance to improve their writing by rewriting their papers"[23]. This practice is also valuable for problem sets; students deserve a chance to improve their problem-solving skills as well. While the value of problem sets is well known, students seem not to review their work in detail once it is returned to them. Many educators note 
the phenomena of students looking for their grade and never looking at their homework again. Even when students review their work, they tend to focus on the parts they got wrong, rather than reinforcing the parts that were correct. Detailed feedback without self-correction was equivalent to no feedback in second language courses[24]. A comprehensive review of all the graded homework will ensure students review all material.

Not only reviewing material, but also engaging and assessing technical material increases retention[4], [23]. This study seeks to build on that best practice by lowering the stakes for completion of a problem set by providing a percentage of the grade for self-evaluation and revision achieved through deliberating marking all correct and incorrect portions of the work. This facilitates metacognition, which is believed to increase learning as well as encourage other behaviors associated with learning such as peer-to-peer collaboration.

The findings related to the use of homework assignments as structured practice of technical skills for engineering students may relate to the broader concept of metacognition, where the learner constantly monitors their learning process assimilating new knowledge to existing mental models[25]. Metacognition is generally broken into two subcomponents: Metacognitive Knowledge and Metacognitive Regulation[26]. Metacognitive Knowledge refers to a realization of a student's own cognitive processes[27], [28]. Metacognitive Regulation addresses a student's strategies to oversee their own learning[28]. Within the metacognitive conceptual framework, the structured review and evaluation of student homework assignments relates to Metacognitive Regulation shown in fig. 1. More specifically, the student evaluated homework process allows students an opportunity to monitor task performance through the review of their work, evaluate their performance by comparing to the 'approved' solution, and gives them the tools to control future problem solving activities to elicit change in their approach. The faculty of the course have done the metacognitive regulation planning for the students by structuring the homework evaluation process in a way that allows the other three processes to occur for each graded event.

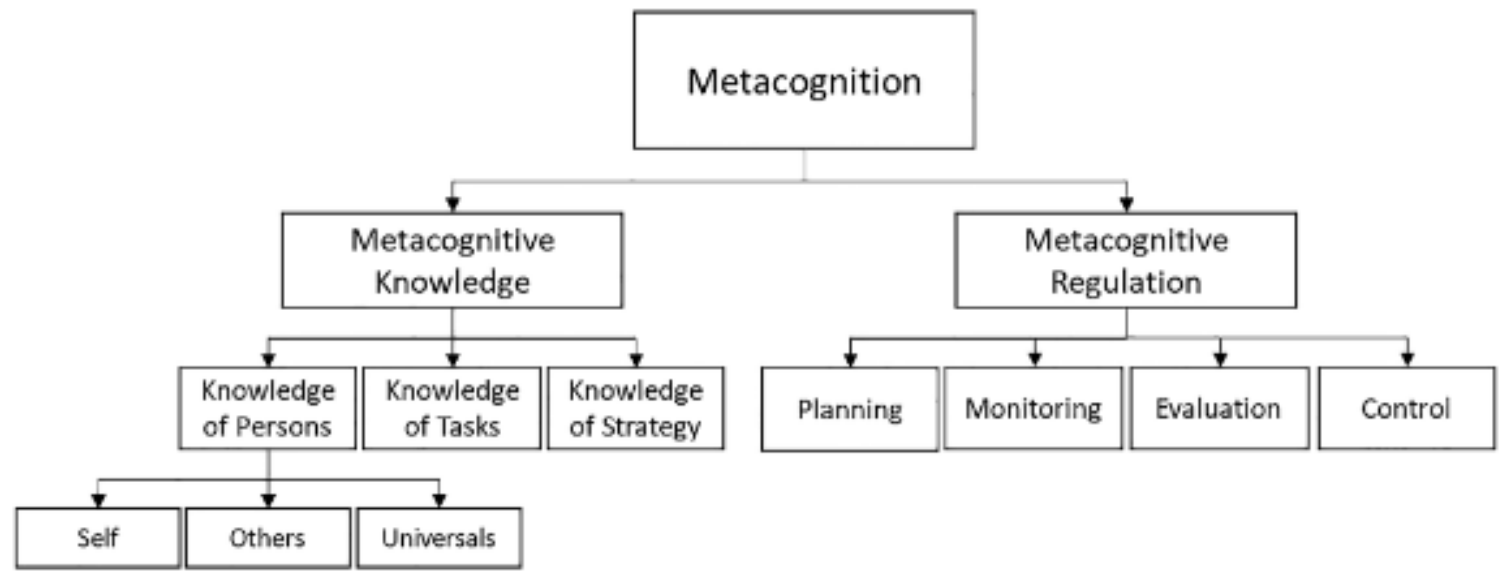

Figure 1: Metacognition conceptual framework[26]

methods

Students initially electronically submitted their homework on the given due date and a detailed "approved" solution is provided by the instructor at the same time. Students then mark errors 
against the posted solution and submit both their original work as well as their mark-ups. To ensure students pay attention to the material, a portion of the overall grade is awarded based on the extent the material is revised while the majority of the grade is based on the correctness of the original submission. If students submit and complete and correct first attempt, then they are given full points without a need for any corrections. If they only have a few small corrections to make, these can be done quickly. In this case, full points are still awarded for the revision position since their strong initial effort ensured that minimal corrections were needed. That said, even small "math errors" require correction in the hopes that these types of errors will be avoided in the future, and as an incentive for the students to check their work prior to turn-in. A key requirement of successfully using this method is that the corrected and revised student work needs to be distinguishable from the original work by the grader. All the classes using the method in this study require that corrections be made in red ink to clearly distinguish it from the student's original. The purpose of the original digital submission is to document the work before the student begins corrections and revisions. It is kept as a deterrent to cheating; students know that any alteration of the original work can be detected. In practice, the instructors have no need to consult the original submission unless there is suspicion of cheating.

The study focused on the self-evaluation and revision method in three undergraduate mechanical engineering courses: dynamics, vibrations, and controls. Dynamics is taught to juniors, while vibrations and controls is traditionally taught to seniors. At West Point, all mechanical engineers are required to take Dynamics, while they may choose between vibrations and controls. Further, the self-evaluation and revision method had been used for multiple years in the vibrations course, while it was re-implemented in both dynamics (it had previously been used in 2013) and newly implemented in controls.

Every course had several homework assignments due per semester. These required about two to four hours of work from the students. Students spent between five- and thirty-minutes working on corrections and revisions. Due to differences in the structure of the course, the self-evaluation and revision method was used differently in every course. Table 1 shows the allocation of points for the original submission as well as the self-evaluation and revision.

Table 1: Point allocation and percentage of mixed-use with traditional grading method

\begin{tabular}{|l|c|c|c|}
\hline & $\begin{array}{c}\text { MC486 } \\
\text { (Vibrations) }\end{array}$ & $\begin{array}{c}\text { MC306 } \\
\text { (Dynamics) }\end{array}$ & $\begin{array}{c}\text { XE472 } \\
\text { (Controls) }\end{array}$ \\
\hline Original submission & $67 \%$ & $75 \%$ & $70 \%$ \\
\hline Graded \& Revised submission & $33 \%$ & $25 \%$ & $30 \%$ \\
\hline $\begin{array}{l}\text { \% of problem sets that used the } \\
\text { technique }\end{array}$ & $100 \%$ & $75 \%$ & $100 \%$ \\
\hline
\end{tabular}

Data was collected from three courses at varying times (five years for one course, and a single year for two other courses). Data was collected at a mid-point in the course and at the end of the course. Data presented is a summary of the end of course data, collected through the USMA course-end 
survey system to ensure student anonymity. While the self-evaluation and revision method was used in teaching dynamics in 2013, end of course survey questions differed from those of the current study. However, student comments from that year are included. A summary of when the self-evaluation and revision method was used is presented in Table 2.

In order to determine student perception and attitudes about the technique, a series of questions were developed to determine the impact of the self-evaluation and revision method on student learning, motivation, and attitudes. These surveys were administered at least once during the semester (usually near the midpoint) and during a course end survey. Recruitment was voluntary. Students who did not want to participate did not have to take the survey. Data was collected on anonymous papers handed out during class for the mid-year survey. Furthermore, the course end survey system anonymizes responses to the questions for both courses and sections within courses. Questions are listed in Table 2.

Table 2: Questions used in the student survey and when it was administered. Semesters are listed as the academic year and then the term (YY-T). Courses are listed using their codes.

\begin{tabular}{|c|c|c|c|c|c|c|}
\hline Question & $13-2$ & $18-1$ & $18-2$ & $19-1$ & $19-2$ & $20-1$ \\
\hline $\begin{array}{l}\text { Q1: The Self-Correcting Method } \\
\text { helped me learn the material better }\end{array}$ & & MC486 & XE472 & MC486 & $\begin{array}{l}\text { MC486, } \\
\text { MC306 }\end{array}$ & MC486 \\
\hline $\begin{array}{l}\text { Q2: The Self-Correcting Method } \\
\text { increased my motivation to } \\
\text { successfully complete the } \\
\text { homework the first time. }\end{array}$ & & MC486 & XE472 & MC486 & $\begin{array}{l}\text { MC486, } \\
\text { MC306 }\end{array}$ & MC486 \\
\hline $\begin{array}{l}\text { Q3: The Self-Correcting Method } \\
\text { was a good use of my time }\end{array}$ & & MC486 & XE472 & MC486 & $\begin{array}{l}\text { MC486, } \\
\text { MC306 }\end{array}$ & MC486 \\
\hline $\begin{array}{l}\text { Q4: The Self-Correcting Method } \\
\text { helped me review topics that I need } \\
\text { to know }\end{array}$ & & & & MC486 & $\begin{array}{l}\text { MC486, } \\
\text { MC306 }\end{array}$ & MC486 \\
\hline $\begin{array}{l}\text { Q5: The Self-Correcting Method } \\
\text { reduced my anxiety about grades. }\end{array}$ & & & & MC486 & $\begin{array}{l}\text { MC486, } \\
\text { MC306 }\end{array}$ & MC486 \\
\hline $\begin{array}{l}\text { Q6: The Self-Correcting Method } \\
\text { reduced time required to study for } \\
\text { exams and the final. }\end{array}$ & & & & MC486 & $\begin{array}{l}\text { MC486, } \\
\text { MC306 }\end{array}$ & MC486 \\
\hline
\end{tabular}




\begin{tabular}{|l|l|l|l|l|l|l|}
\hline $\begin{array}{l}\text { Q7: The Self-Correcting Method } \\
\text { helped me learn better than } \\
\text { traditional homework methods. }\end{array}$ & & & & MC486 & $\begin{array}{c}\text { MC486, } \\
\text { MC306 }\end{array}$ & MC486 \\
\hline $\begin{array}{l}\text { Q8: The Self-Correcting Method } \\
\text { makes me aware of my } \\
\text { own problem-solving thought } \\
\text { process }\end{array}$ & & & & & & MC486 \\
\hline
\end{tabular}

Since the primary motivation for introducing this new method of completing homework was improving student learning, we asked three questions about this. Q1 was a relatively open-ended question that asked students if the method a good way to learn the material, in general. Q4 was designed to determine if reviewing the questions soon after getting them wrong helps the students. Q7 specifically asked students to compare the self-evaluation and revision method to standard homework grading methods in terms of student learning.

Q2 assesses whether the method motivates students to complete the homework successfully the first time. It compares this homework grading method to the method described in the previous study[22]. In the previous study, students were required to rework problems until they got them correct, using both a point penalty and a time penalty as motivators.

Q3 and Q6 assess the impact the method had on students' time management. The first reason this is of interest is that students are quite busy, and we do not wish to arbitrarily make them even busier. Secondly, the instructors were concerned that if the time burden was too high, that it would erode the students' attitudes about the method, and therefore erode its effectiveness. Finally, Q6 assesses whether reviewing the homework topics after it was due results in a more efficient studying for exams.

Q5 measures whether the self-evaluation and revision method had a positive impact students' anxiety about grades, which can be significant in these courses, at least anecdotally, based on conversations with students. Q8 attempted to determine if the method helped students learn about themselves as well as about the homework topic.

Notes to future users

There are several aspects of this technique that the authors learned over the course of time as different features emerged in the courses that adopted the method. The first consideration is the quality and thoroughness of the instructor-published solution. Since problems are rarely assigned straight from the textbook, ready-made solutions are not available, and the instructor must generate their own solutions. It also avoids the problem of publishing a textbook solution to students. Instructors must consider the level of detail they provide to the students in the solution. As experts in their field, sometimes instructors provide efficient solutions that skip simple steps. In the author's experience, this often causes questions and confusion; a thorough solution that does not skip steps was found to be best. Some instructors would also provide commentary during different parts of the solution writing process, either referring to comments or discussion from class, or highlighting particularly tricky areas. These annotated solutions can contain many of the comments 
that the graders would inevitably write on many different student papers if they were doing standard grading. With the self-correcting method, these comments are given only once, up front, in a solution.

There is therefore a significant upfront cost associated with preparing these solutions, although this work can be performed by a teaching assistant if one is available. It may seem this work is wasted, since students will be able to share the solution with online repositories or with students who take the course in the future. Our experience has been that even when an instructor solution is not present, a solution already exists and new problems must be generated regardless of instructor solutions. More time is spent in crafting a problem that addresses the nuances of the material than the solution. Also, this system almost ensures the solution is shared, which helps educators recognize the need to craft new problems, since informal solutions from outstanding student work is already shared. Experience shows this not to be too much of a time burden compared to generating new problems and solutions for the instructor to grade from. There are secondary benefits to a high-quality solution in-and-of itself as it sets a high standard for student work. It models quality work and inspires students to ensure their own homework submission are neat.

Using this self-evaluation and revision method changes how grading is performed by the instructor or grader (in cases where a teaching assistant performs the grading). There are two separate elements to grading the final submission, but they can be performed simultaneously. The first element of grading is to review the corrections that the student made. The grader must check that the original student work was corrected or modified so as to reflect a corrected understanding of the concept. In-line corrections are preferred, which usually requires the student to space their original work out appropriately, and neatness is rewarded. If the original submission is almost completely worked, the "correction" largely becomes an aided rework of the problem. At this point, copying of the solution is possible, but discouraged. In such a situation, the student would get a very low grade on the original submission and then get a very high grade on the "corrections" portion of their submission. Given the weighting between each assignment, the overall grade is still failing. In either case, the first part of the grading is to assign a score to the corrections themselves based on how complete and accurate the corrections are.

The second element of grading the final submissions is to confirm or revise the students' own selfassessment (when they assign a letter grade to their complete homework set). This self-assessment provides an indication of the student's comfort level with the material. Furthermore, it reinforces the habit of self-reflection, which is a key component of developing as leaders of character. Finally, we feel that this is an important aspect of metacognitive regulation, where students must evaluate their work as objectively as possible[28]. However, instructors rarely take these scores at face value. After reviewing the extent of the corrections and the types of mistakes that the students made, it is relatively easy to assess whether or not the students' self-grades are accurate. If they are not, then the grader simply revises the grade and replaces it with something more representative of what they should have given themselves in the first place. In our experience, it is equally common for the grader to adjust a self-graded score up as it is to adjust the score down. Over time, in our experience, the students get a little better at assessing their own work, but an experienced grader is always needed. 
Although the two-part grading might sound like it increases the grading workload, it typically does not. It is usually more efficient to review their self-corrections than to grade a homework set from scratch. That said, for very low enrollment courses, the upfront cost of making a high-quality solution for the student can outweigh any efficiencies gained after the final submission. For larger enrollment courses, it can reduce the overall grading burden substantially because the work of identifying the mistakes and then correcting them has been done by the student. In our experience, the breakeven point is about 20 students--for courses smaller than 20 students, it is probably more work to effectively run the self-correcting method, and for courses with more than 20 students, it is less work to have the student self-correct. The method is most useful in courses like dynamics where the problems are complex, and the concepts are difficult. It mitigates the need for the grader to follow calculations step-by-step in search of errors - the student should do this, not the grader.

How the grading method is introduced is important. Students are typically provided with a hard copy of the instructions on the first day of class and then the instructor dedicates ten minutes of class to clearly detail how it works. While doing so, the instructor also takes care to extol the merits and benefits of the method. This helps to put the students' concerns about it to rest, and it also provides an opportunity to emphasize the motivation for using this method (that instructors firmly believe the students will learn more by doing it).

There are inevitably some special situations that also need to be addressed. For example, a common question is what happens if someone gets a perfect score on the first submission--do they get zero points on the revision? In this situation, they get full points on the revision as well for obvious reasons. High achieving students can cause other issues to arise. First, occasionally a student will work well in advance of his or her peers and find an error in the instructor-provided solution. When this occurs, the student who identifies the error is rewarded with a few bonus points. The instructors then correct the solution and repost it. Additionally, sometimes students will create valid solutions using a different method. If they simply arrive at the right answer using a different approach, they naturally get full credit. But if they are willing to prepare a version of the solution for public dissemination for the benefit of their peers, they can also be compensated for their time with additional points. It is possible to produce the correct answer, but the method or calculations are not correct. Students must do more than simply comparing their final answer to the solution- they must compare solution methods.

Another special case deals with student-written code. The courses in this study utilize MATLAB ${ }^{\circ}$, and when there is a coding portion of a homework assignment, the students are expected to publish their code with appropriate comments and section breaks. The instructor also provides published code as well. In order for the students receive full credit on their revisions/corrections, they need to correct their code and get it working properly. We strongly prefer that students fix their own code rather than simply copy and paste code from the instructor solution. Therefore, copying code from the instructor results in a significant point deduction for the revision/correction portion of the homework. Furthermore, since students cannot use "red ink" in their code in order to denote which portions are revised from their original submission, they must clearly comment sections where they have applied revisions.

Results and discussion 
The first and most important question is whether students benefit from using this method. The easiest way to gauge this is by directly asking students whether they prefer the self-evaluation and revision method to standard grading methods. While this is not the most accurate, it does provide a good starting point for determine the efficacy of the method. Students showed a preference for the method, as depicted in fig. 2. MC306 is the only course that shows a weak preference. This could be due to younger students taking the course, or the method was deployed poorly. Instructors for MC306 had never previously used the self-evaluation and revision method in AY19-1, while instructors had used the method previously in all other courses. Initial solutions for MC306 were of poorer quality, which could have started students with a bad image of the method. All courses also showed some level of students who did not favor the method. This could be due to some student experience/preference that will never favor this method or just to general student dissatisfaction.

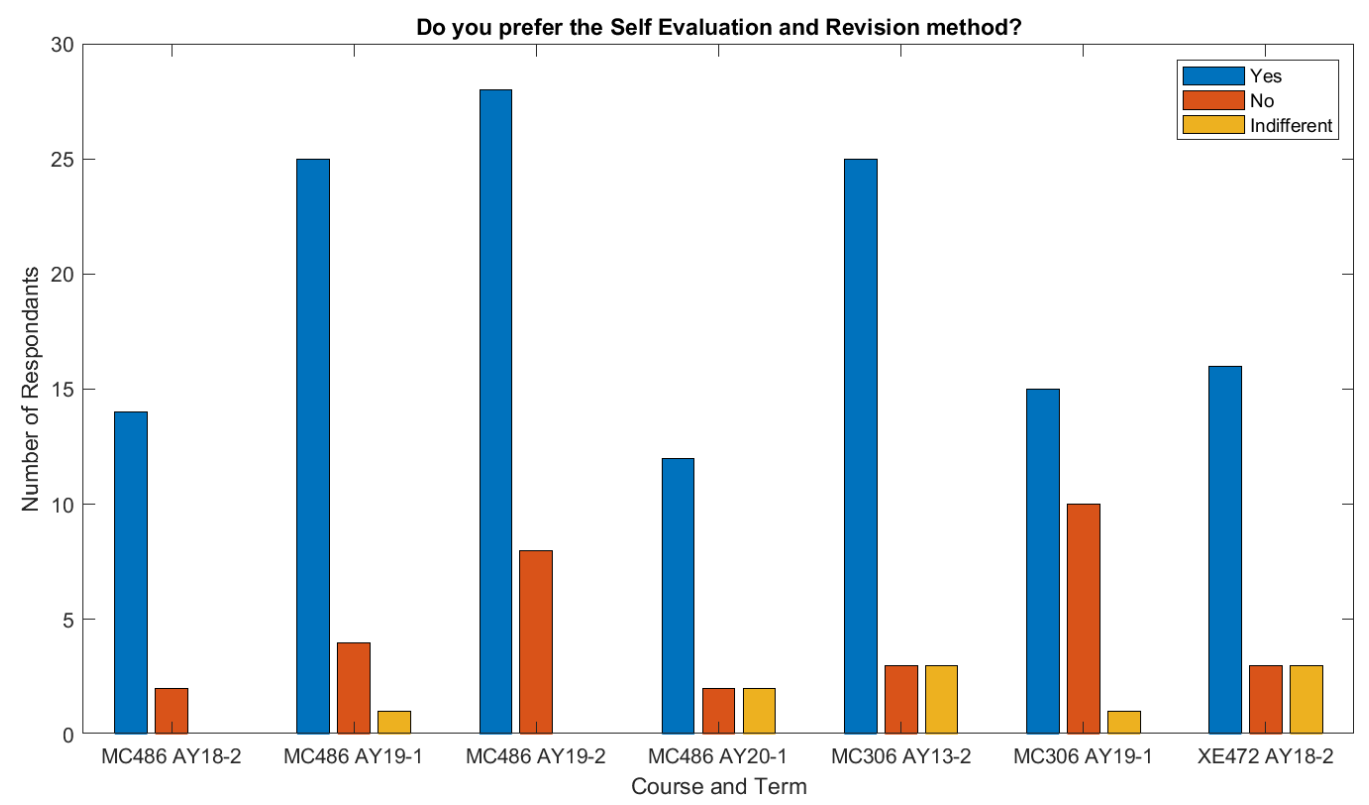

Figure 2: Student responses to the question, "Do you prefer the self-correcting problem set method?" across multiple courses and multiple semesters.

Students showed a positive attitude for the self-evaluation and revision method (see fig. 3). Students rated Q1, Q4, and Q5 highest, indicating that students felt the method was effective. Results from Q4 highlight the metacognitive nature of the revision and supports the conclusion that students were able to better target their studies for those areas with which they needed the most help.

Q2 results indicate that students put in less effort initially, or at least their motivation for the first attempt was reduced. This, however, may indicate that better learning was occurring as students structured the work knowing they would review it. This could indicate students did a good attempt but came back to the revision motivated to make changes. It could also indicate that effort was low, but corresponding decrease in test scores does not match a decrease in performance. 


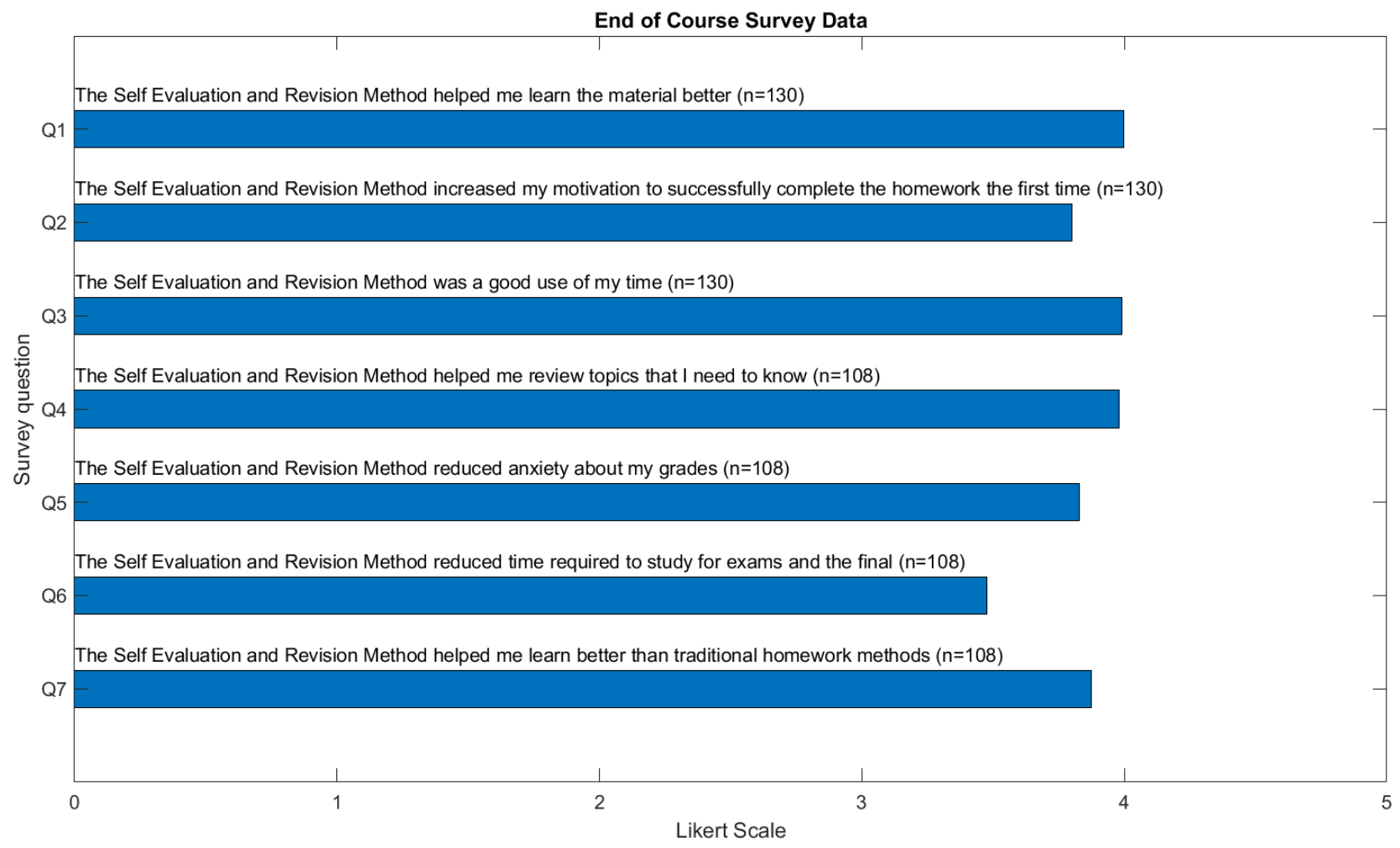

Figure 3: Student responses across all courses in the study collected during the end of course survey. All responses across all courses were weighted equally for each student.

Student attitudes for the self-evaluation and revision method improved from early semester to the end of the term. Early semester surveys were collected between the first third and halfway through the course. Results are presented in fig. 4. The only question to worsen in terms of attitude was Q4. Students assessed the method lowest in its ability to provided value for reviewing topics they did not need to know. The high Likert score but lowest value relative to the survey shows that it may have forced students to review all material, rather than the more targeted review of just what they needed. Further study is needed to determine if that is the case. The largest increase occurred in survey questions came from Q2, with an increase from 3.325 to 3.755 . 


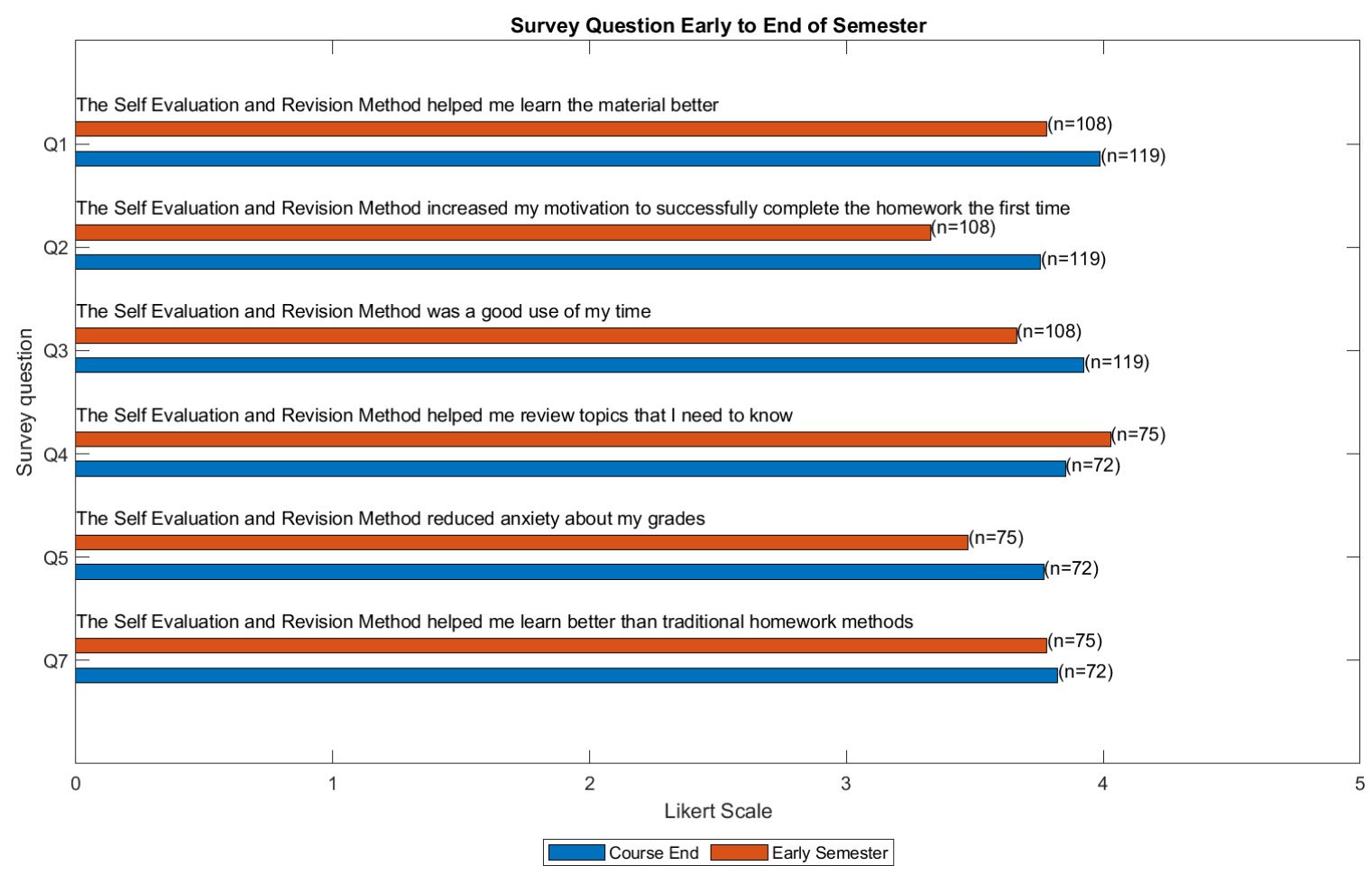

Figure 4: Student responses from early semester to course end. Only courses that had early and end of course data is included. All responses across all courses were weighted equally for each student. Early semester survey was conducted between the first third and half of the course.

\section{Feedback from students}

Themes emerge from the analysis of end-of-course written responses. By far the most common theme is that students appreciate the opportunity to learn from their mistakes. Less frequently, students recognize that the review was beneficial even though it was forced. A small number of students mentioned an appreciation for the opportunity to "get it right," i.e. they valued the completeness and correctness of their work.

Two comments from a dynamics class highlight the benefits of the method:

"I liked the problem set grading method. It actually stimulated my learning, because I had to go back and make corrections. I can honestly say without a doubt it contributed to my learning immensley [sic]."

"Self-Review of problem sets helped me to better understand the problem method, and where i was making mistakes. Previously I just moved on after each problem set without reviewing my mistakes."

Other positive comments revealed that students liked the method for multiple reasons:

Immediate feedback is appreciated.

It helps students self-assess mastery

It emphasizes learning, not just grades.

It makes students responsible for their own learning. 
The majority of student feedback is positive, but a small number of students prefer the traditional grading method and convey the following themes:

It seems like double work, or it takes more time.

It's not fair because some students grade themselves leniently [sic].

In general, these comments help to reinforce instructor satisfaction with the method as well as demonstrate that the metacognitive framework for better learning seems to be supported.

Survey of instructors

Instructors who taught using the self-evaluation and revision method were surveyed about their perceptions. Six instructors responded. The instructors were asked questions that correspond to the student questions Q1 through Q7. Responses were on a Likert scale from "Strongly Disagree" to "Strongly Agree." Responses were converted to numerical scores from 1 to 5. Results are listed in Table 3. Instructors were more favorable toward the method than students on all seven questions.

Table 3: Corresponding questions of the instructor survey. $\mathrm{N}=6$.

\begin{tabular}{|l|c|}
\hline Question & $\begin{array}{c}\text { Average } \\
\text { (scale 1-5) }\end{array}$ \\
\hline Q1: The Self-Correcting Method helped my students learn the material better & 4.2 \\
\hline $\begin{array}{l}\text { Q2: The Self-Correcting Method increased my students' motivation to } \\
\text { successfully complete the homework the first time }\end{array}$ & 3.3 \\
\hline Q3: The Self-Correcting Method was a good use of my students' time & 4.5 \\
\hline $\begin{array}{l}\text { Q4: The Self-Correcting Method helped my students review topics that they } \\
\text { need to know }\end{array}$ & 4.5 \\
\hline \begin{tabular}{l} 
Q5: The Self-Correcting Method reduced my students' anxiety about grades \\
\hline $\begin{array}{l}\text { Q6: The Self-Correcting Method reduced time students spent studying for } \\
\text { exams }\end{array}$
\end{tabular} & 4.0 \\
\hline $\begin{array}{l}\text { Q7: The Self-Correcting Method helped my students learn better than } \\
\text { traditional homework grading methods }\end{array}$ & 4.4 \\
\hline
\end{tabular}

Instructor scores greater than students are likely associated with pre-existing bias that the method is beneficial, since instructors chose to use the method in their courses. However, it does show that all instructors who implemented this system prefer it to traditional methods. 
Instructors were asked three additional questions. Responses are listed in Table 4. The instructors indicated agreement with Q8 and Q9, but disagreement with Q10. Concerns about cheating are reasonable, especially since an instructor solution is given out to all students. Subsequent iterations of the course need to use unique homework to ensure that approved solutions are not used prior to the homework submission.

Table 4: Additional questions of the instructor survey. $\mathrm{N}=6$.

\begin{tabular}{|l|c|}
\hline Question & $\begin{array}{c}\text { Average } \\
\text { (scale 1-5) }\end{array}$ \\
\hline $\begin{array}{l}\text { Q8: On average I spend less time grading problem sets with this method than } \\
\text { with traditional grading methods }\end{array}$ & 4.3 \\
\hline $\begin{array}{l}\text { Q9: The Self-Correcting Method helps me emphasize the value of complete } \\
\text { and correct work to my students }\end{array}$ & 4.5 \\
\hline $\begin{array}{l}\text { Q10: I am concerned that the Self-Correcting Method introduces opportunities } \\
\text { for students to cheat }\end{array}$ & 2.3 \\
\hline
\end{tabular}

Instructors were asked "For classes you taught using the Self-Correcting Method for problem sets, did you prefer it over the standard instructor-correcting homework grading method?" All instructors responded "Yes." Immediately following this question instructors were asked why they preferred or did not prefer it. Even with only six instructors, a comprehensive list of features of the method were documented in their responses, see Table 5. Comments that favor the method are coded green; neutral comments are coded yellow, comments against the method are coded pink.

Table 5: Themes contained in instructor survey. $\mathrm{N}=6$.

\begin{tabular}{|l|l|l|l|l|}
\hline Student-Centered themes & Count & Positive & Neutral & Negative \\
\hline Feedback is timely & 2 & & & \\
\hline Help is targeted & 1 & & & \\
\hline Students learn from mistakes & 2 & & & \\
\hline Students engage more & 2 & & & \\
\hline $\begin{array}{l}\text { Encourages students to take responsibility for } \\
\text { learning }\end{array}$ & 1 & & & \\
\hline Students see a model solution & 2 & & & \\
\hline Benefits more mature students & 1 & & & \\
\hline
\end{tabular}




\begin{tabular}{|c|c|c|c|c|}
\hline Struggling students were not thorough & 1 & & & \\
\hline Instructor-Centered themes & Count & Positive & Neutral & Negative \\
\hline Relieves grading burden 2 (positive) & 1 & & & \\
\hline $\begin{array}{l}\text { Helps instructor evaluate student mastery } \\
\text { (positive) }\end{array}$ & 1 & & & \\
\hline $\begin{array}{l}\text { Does not help Instructor evaluate mastery } \\
\text { (negative) }\end{array}$ & 1 & & & \\
\hline
\end{tabular}

Other impacts of the self-evaluation and revision method

In the authors' collective experience, course averages for grades on homework sets is often higher than course averages for in-class exams. Although not specifically studied, there are seemingly obvious reasons for this difference. The first reason is that homework is not a timed event, whereas in-class exams are. Additionally, students can get help from each other and from their instructors on homework sets, whereas an exam is strictly an individual assignment. We also wished to determine how the self-evaluation and revision method changed the grades on homework sets, if at all. In our experience, the average homework grades are higher than the course average for the exams. Indeed, homework scores appear to be higher using the self-evaluation and revision method than using standard grading methods, although only a by little (approximately 1\%). Data from the vibrations course is presented in Table 6 that shows the difference. This is typical for courses that use the self-evaluation and revision method. The primary motivation for using the method is the increased potential for student engagement and learning.

Table 6: Comparison of grades for MC486 (Vibrations) using a standard homework grading method (during academic year 2016), and using the self-evaluation and revision method (in academic year 2018).

\begin{tabular}{|c|c|c|c|}
\hline Period & Event & $\begin{array}{c}\text { Standard } \\
\text { (AY16) }\end{array}$ & $\begin{array}{c}\text { Self-evaluation and revision } \\
\text { (AY18) }\end{array}$ \\
\hline \multirow{2}{*}{ first block } & HWs & $87.7 \%$ & $88.8 \%$ \\
\cline { 2 - 4 } & Exam & $79.6 \%$ & $86.9 \%$ \\
\hline \multirow{2}{*}{ second block } & HWs & $82.2 \%$ & $83.4 \%$ \\
\cline { 2 - 4 } & Exam & $75.6 \%$ & $77.6 \%$ \\
\hline comprehensive & Final & $78.5 \%$ & $81.1 \%$ \\
\hline
\end{tabular}

A comprehensive evaluation of the method's ability to increase test scores as a measurement for 
learning is still required. Data shows either no change or a small increase in grades (less than 3\% change in average). However, differences in instructors, incoming student grades, and other factors likely contribute to any variance in the grade data.

\section{Conclusion}

The purpose of this paper is to describe an alternative method for assigning and grading homework problems. The goal is to increase student learning by making them self-evaluate their work, correct any errors that they identified, which enables them to monitor their own cognitive processes at multiple levels. It also corrects misconceptions early and can facilitate faster comprehension. The method also appears to improve students' attitudes. There seem to be differences between courses, but further study is required to determine if the differences are due to student grade level, instructor training with the method, or some other factor related to the course material. There are some drawbacks to the method including the increased possibility for student cheating, but nonetheless instructors preferred the method overwhelmingly.

\section{References}

[1] R. Wieman and F. Arbaugh, "Making Homework More Meaningful," Math. Teach. Middle Sch., vol. 20, no. 3, pp. 160-165, 2014.

[2] B. Walvoord and V. Anderson, Effective Grading: A Tool for Learning and Assessment. San Francisco: Jossey-Bass, 1998.

[3] J. R. Grohs, T. Kinoshita, B. J. Novoselich, and D. B. Knight, "Exploring learner engagement and achievement in large undergraduate engineering mechanics courses," ASEE Annu. Conf. Expo. Conf. Proc., vol. 122nd ASEE, no. 122nd ASEE Annual Conference and Exposition: Making Value for Society, 2015, doi: 10.18260/p.24066.

[4] D. Ryan and M. Woong-Dodge, "Sel-correcting exams: Making the summative, formative," in National Institute on the Teaching of Psychology, 2009.

[5] H. Cooper, "Synthesis of Research on Homework.pdf," Educ. Leadersh., no. November, pp. 85-91, 1989.

[6] L. Hirsch and C. Weibel, "Statistical evidence that web-based homework helps," MAA Focus Newsmag. Math. Assoc. Am., vol. 23, no. 2, p. 14, 2003.

[7] M. Richards-Babb, J. Drelick, Z. Henry, and J. Robertson-Honecker, "Online Homework, Help or Hindrance? What Students Think and How They Perform.," J. Coll. Sci. Teach., vol. 40, no. 4, pp. 81-93, 2011, doi: 10.3102/00346543076001001ไr10.1021/ed081p441.

[8] R. D. Arasasingham, I. Martorell, and T. M. McIntire, "Online homework and student achievement in a large enrollment introductory science course," J. Coll. Sci. Teach., vol. 40, no. 6, pp. 70-79, 2011.

[9] J. Roschelle, M. Feng, R. F. Murphy, and C. A. Mason, "Online Mathematics Homework Increases Student Achievement," AERA Open, vol. 2, no. 4, p. 233285841667396, 2016, doi: $10.1177 / 2332858416673968$.

[10] R. A. and T. Williams, "The Effectiveness of Online Homework in an Introductory Science Class,” J. Coll. Sci. Teach., vol. 35, no. 6, pp. 28-31, 2006.

[11] S. Hauk, R. A. Powers, and A. Segalla, "A Comparison of Web-based and Paper-andPencil Homework on Student Performance in College Algebra," Primus, vol. 25, no. 1, pp. 61-79, 2015, doi: 10.1080/10511970.2014.906006. 
[12] J. T. Callahan, “Assessing Online Homework in First-Semester Calculus," Primus, vol. 26, no. 6, pp. 545-556, 2016, doi: 10.1080/10511970.2015.1128501.

[13] P. G. Larose, "The impact of implementing web homework in second-semester calculus," Primus, vol. 20, no. 8, pp. 664-683, 2010, doi: 10.1080/10511970902839039.

[14] J. C. Mitchell and J. E. Mitchell, "Using Web-Based Homework To Teach Principles Of Microeconomics: A Preliminary Investigation," Am. J. Bus. Educ., vol. 10, no. 1, pp. 916, 2016, doi: 10.19030/ajbe.v10i1.9849.

[15] S. Bonham, R. Beichner, and D. Deardorff, "Online homework: Does it make a difference?," Phys. Teach., vol. 39, no. 5, pp. 293-296, 2001, doi: 10.1119/1.1375468.

[16] C. Halcrow and G. Dunnigan, "Online Homework in Calculus I: Friend or Foe?," Primus, vol. 22, no. 8, pp. 664-682, 2012, doi: 10.1080/10511970.2012.694015.

[17] R. Dufresne, J. Mestre, D. M. Hart, and K. A. Rath, "The Effect of Web-Based Homework on Test Performance in Large Enrollment Introductory Physics Courses," $J l$. Comput. Math. Sci. Teach., vol. 21, no. 21(3), pp. 229-251, 2002.

[18] D. Koban, M. Fukuzawa, R. Slocum, M. Fletcher, and J. Pleuss, "Differential Effects of Incentivized Homework on Student Achievement in Undergraduate Mathematics," Primus, vol. 0, no. 0, pp. 1-19, 2019, doi: 10.1080/10511970.2018.1530703.

[19] W. Y. Hwang, N. S. Chen, R. Shadiev, and J. S. Li, "Effects of reviewing annotations and homework solutions on math learning achievement," Br. J. Educ. Technol., vol. 42, no. 6, pp. 1016-1028, 2011, doi: 10.1111/j.1467-8535.2010.01126.x.

[20] E. Hong, R. M. Milgram, and L. L. Rowell, "Homework motivation and preference: A learner-centered homework approach," Theory Pract., vol. 43, no. 3, pp. 197-204, 2004, doi: 10.1353/tip.2004.0036.

[21] A. W. Chickering and Z. F. Gamson, "Seven Principles for Good Practice in Undergraduate Education," Am. Assoc. High. Educ. Bull., no. Mar, pp. 3-7, 1987, doi: 10.5551/jat.Er001.

[22] J. Bluman, M. Rowland, and E. Mockensturm, "Closing the homework feedback loop, an alternative approach to homework grading," in Proceedings - Frontiers in Education Conference, FIE, 2010, pp. 1-6, doi: 10.1109/FIE.2010.5673373.

[23] B. G. Davis, Tools for Teaching, 1st ed. San Francisco: Jossey-Bass, 1993.

[24] J. Chandler, "The efficacy of various kinds of error feedback for improvement in the accuracy and fluency of L2 student writing," J. Second Lang. Writ., vol. 12, no. 3, pp. 267-296, 2003, doi: 10.1016/S1060-3743(03)00038-9.

[25] W. C. Newstetter and M. D. Svinicki, "Learning theories for engineering education practice," in Cambridge Handbook of Engineering Education Research, Cambridge University Press, 2014, pp. 29-46.

[26] R. E. McCord and H. M. Matusovich, "Naturalistic observations of metacognition in engineering: Using observational methods to study metacognitive engagement in engineering," J. Eng. Educ., vol. 108, no. 4, pp. 481-502, 2019, doi: 10.1002/jee.20291.

[27] A. Brown, "Metacognition, Executive Control, Self-Regulation and Other More Mysterous Mechanisms," in Metacognition, Motivation and Understanding, F. Weinert and R. Kluwe, Eds. Hillsdale, 1987, pp. 65-116.

[28] J. H. Flavell, "Metacognition and cognitive monitoring: A new area of cognitivedevelopmental inquiry," Am. Psychol., vol. 34, no. 10, pp. 906-911, Oct. 1979, doi: 10.1037/0003-066X.34.10.906. 